\title{
To Make Good Compression Wears with Moderate Pressure
}

\section{Opinion}

\author{
Tamaki Mitsuno* \\ Shinshu University, Japan \\ *Corresponding author: Tamaki Mitsuno, Shinshu University, 6-Ro, Nishinagano, Nagano-shi, Nagano, Japan
}

submission: 監June 06, 2018; Published: 眥June 08, 2018

\section{Opinion}

Clothing pressure as an index of clothing comfort has been well studied. The pressure applied by clothing has advantages and disadvantages [1]. Compression wear has become popular for controlling body shape and for reducing swelling in daily life. Moderate pressure is needed to achieve a beautiful silhouette while excessive pressure has adverse effects [2]. According to Kikufuji et al. [3] menstrual cycles were significantly delayed by 14 days when participants wore a tight foundation layer of clothing compared with when they wore no foundation layer [3]. Meanwhile, Sugimoto reported an increase in urinary noradrenaline excretion when participants wore a girdle. It is possible that the pressure may cause the alternation of the autonomic nervous system [4]. It is therefore important to pay careful attention to the level, duration and frequency of pressure being applied to a particular body part [5]. Among body parts, the legs are most insensitive to pressure and commercial compression ware products that reduce swelling of the legs [6] are widely available [7]. Meanwhile the abdomen was sensitive for the clothing pressure compared with legs. The skin is not equally sensitive all over the body, because the mechanoreceptors are not equally dense all over the body [8] Perhaps, the body surface of abdomen will have mechanoreceptors more than the legs. The abdomen is a body part requiring very careful attention for pressure. However, the abdomen becomes the body part where a good effect is provided if moderate pressure can be realized. When the abdomen was supported by moderate pressure, an example of body fat consumption (BFC) was described as follows. At first BFC by aerobic exercise was examined without clothing pressure as possible.

\section{Discussion}

\section{Aerobic exercise without clothing pressure}

Physical exercise is important for limiting fat mass and preventing obesity $[9,10]$. Aerobic exercise after breakfast is effective in helping to maintain BFC. Study subjects were 18 young Japanese women who did not exercise regularly. They then engaged in $30 \mathrm{~min}$ of aerobic exercise with loads that were equivalent to $25 \%$,
$40 \%, 55 \%, 70 \%$, and $25 \%$ of the maximum heart rate in sequential 6-minute intervals. Respiratory metabolism and heart rate were measured with a bicycle ergo meter. The amount of energy, lipid, and carbohydrate consumed were calculated from respiratory quotients. Energy/carbohydrate consumptions and relative heart rates increased significant compared with the resting control, which increased linearly as exercise load increased. Conversely, no significant differences were found in BFC across exercise stages. These results showed that the effect of increasing BFC was not obtained, even if the intensity of exercise was increased. Thus, it was not necessary to increase the exercise load to burn BFC with aerobic exercise. Using path analysis, we found that it is necessary to prevent relative heart rate and carbohydrate consumption increases to create an increase in BFC with adequate oxygen intake during exercise. Our findings show that aerobic exercise at a level to increase relative heart rate $20 \%-30 \%$ was effective in reducing body fat in women who do not exercise regularly [11].

\section{Aerobic exercise with three support pants}

Support pants: Furthermore the effects of wearing support pants were confirmed. The exercise program given subjects was the same method described previously. Twenty-one young Japanese women completed aerobic exercise sessions while wearing each of four types of support pants. Subjects worn the same shortsleeved $100 \%$ cotton t-shirt and one of the following: $100 \%$ polyester running pants (A), basic compression pants with 8.9 Tex (80D) yarn (B), 8.9 Tex (80D) yarn pants designed to provide partial compression (C), 12.2 Tex (110D) yarn pants with the same design as C (D). Pants A provided almost no compression, pants $B$ supported the lower abdomen and thighs uniformly, and pants $\mathrm{C}$ and D provided varying amounts of partial compression, particularly over the lower abdomen and medial thigh [5]. The basic knitting structure of these compression pants were single-rib stitches. The tensile force and strain were measured using by KES (FB1-AUTOA, Kato Tech, Kyoto, Japan) under the following condition; Speed: $0.2 \mathrm{~mm} / \mathrm{s}$, Chuck: $5.0 \mathrm{~cm}$, Maximum load: $50 \mathrm{gf} / \mathrm{cm}$. The compression pants were easy to be stretched out to the wale direction in order 
to Pants B,C,D and more hysteresis was observed. From this, the knitting structure in Pants B was easy to lengthen, but is hard to return. On the other hand, Pants D was hard to lengthen, and was easy to return. The clothing pressures (CP) of pants B,C and D were measured by the hydrostatic pressure-balance method [12]. The 33 CP measurement sites, which were all on the right side of the body were measured each subject. The mean \pm SD of CPs were $3.7 \pm 2.8 \mathrm{hPa}$ in $\mathrm{B}, 4.9 \pm 3.4 \mathrm{hPa}$ in $\mathrm{C}, 6.2 \pm 3.9 \mathrm{hPa}$ in D. Each subject's perception of pressure while wearing the experimental pants was examined by questionnaire using a visual analogue scale [13]. Pants B were evaluated as feeling like "a perfect fit", while pants C and D were evaluated as "slightly tight" and "tight feeling", respectively.

BFC during aerobic exercise wearing support pants: Total $\mathrm{BFC}$ during aerobic exercise was 16 times greater than at rest. Partial compression garments (C,D) helped reduce body fat more efficiently than either non-compression (A) or constant compression garments (B). Our findings revealed that partial compression garments (pants $\mathrm{C}$ and $\mathrm{D}$ ) enhanced exercise-associated reductions in body girth and fat more efficiently than non-compression (pants A) or constant compression (pants B) garments (1.5 times greater). In particular pants $\mathrm{C}$, which were designed with belt-shaped elasticized tapes running from the medial thighs to the buttocks with their muscular fiber, enhanced $\mathrm{BFC}$ even without exercise (1.4 times greater than pants A/B). Thus, wearing this type of partial compression pant both during exercise and during general daily activities may be an easily achieved strategy for obesity prevention [14]. A pressurization wear should be support wear not compression wear in daily life.

\section{Conclusion}

The pressure applied by clothing has advantages and disadvantages. It is therefore important to pay careful attention to the level, duration and frequency of pressure being applied to a particular body part. The abdomen was sensitive for the clothing pressure compared with legs. However the abdomen is supported by moderate pressure, the increasing lipid consumption was describe. Total BFC during aerobic exercise was 16 times greater than at rest. Furthermore, the lipid consumption with wearing partial compression pants was increased 1.5 times than with wearing no compression/constant pressure pants. A pressurization wear should be support wear not compression wear in daily life.

\section{Acknowledgement}

This work was supported by JSPS Kakenhi (grant number 17H01954).

\section{Conflict of Interest}

Because Mr. Yoshida (Fukusuke Company) produced experimental pants B,C,D which was designed different condition by author; there is not the competition of the result among pants B,C,D.

\section{References}

1. Tamura T (2000) Ifukuatsu no Kouzai (Clothing pressure for merit and demerit). Journal of Home Economics of Japan 51: 1089-1092.

2. Watanuki S, Murata H (1994) Effects of wearing compression stockings on cardiovascular response. Ann Physiol Anthrop 13(3): 121-127.

3. Kikufuji N, Tokura H (2002) Distrubance of the duration in the menstrual cycle under the influence of tight clothing. Biological Rhythm Research 33: 279-285.

4. Sugimoto H (1991) Compression of body by clothing. Increase in urinary norepinephrine excretion caused by foundation garments. Jpn J Hyg 46(2): 709-714.

5. Mitsuno T, Goto R, Ueda K (1998) Effect of pressure stimulation to the waist on the skin temperature of the hand. Sen'i Gakkaishi 54: 555-561.

6. Mitsuno T, Ando T, Shinga I (2010) Leg wear. Concessioner: Okamoto Corporation, JPN Patent No. 5721972, (2011) US patent No.20110314591 (Leg garment), (2011) EP patent No. 2399556A2 (Compressive leg garment), (2015) CN patent No. CN102293451 B (袜子).

7. Mitsuno T, Wang L, Padhye R (2018) Effect of bandage/stocking size on clothing pressure. TBIS 2018 International Symposium, England, UK.

8. Weinstein S (1968) Intensive and extensive aspects of tactile sensitivity as a function of body part, sex and laterality. First Int' l sylmp On the Skin Senses pp. 195-222.

9. Japan Ministry of Health Labour and Welfare (1996) Basic directionality of the illness measures that focused its attention on a lifestyle.

10. Galgani J, Ravussin, E (2008) Energy metabolism, fuel selection and body weight regulation. Int J Obes 32(7): S109-S119.

11. Mitsuno T, Nagayasu M, Shinohara Y, Ando Y (2017) Most effective exercise load for burning body fat with aerobic exercise in young Japanese women. Advances In Human Factors And Ergonomics In Healthcare And Medical Devices, Advances In Intelligent Systems And Computing 590: 205-215.

12. Mitsuno T, Ueda K (2010) Time relation among clothing pressure developed at waistband, respiratory movement, and girth of abdomen. Sen'i Gakkaishi 66(1):74-81.

13. Bijur PE, Silver W, Gallagher MAE (2001) Reliability of the visual analog scale for measurement of acute pain. Acad Emerg Med 8(12): 11531157.

14. Mitsuno, T, Hibino, A (2016) Which support pants are the most effective for burning body fat? Journal of Fiber Bioengineering and Informatics 9(4):187-199. 
Creative Commons Attribution 4.0 International License

For possible submissions Click Here
TTEFT |

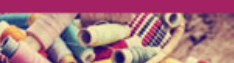

Trends in Textile Engineering \& Fashion Technology

\section{Benefits of Publishing with us}

- High-level peer review and editorial services

- Freely accessible online immediately upon publication

- Authors retain the copyright to their work

- Licensing it under a Creative Commons license

- Visibility through different online platforms 